\title{
ExeCutivos Brasileiros: NA CONTRAMÃo do PERFIL DEIFICADO DA LIDERANÇA TRANSFORMACIONAL
}

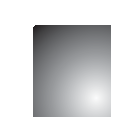

\author{
Brazilian executives: in the opposite sense of the \\ transformational leadership deified profile
}

\begin{abstract}
Antonio Carvalho Neto
Professor do Programa de Pós-Graduação em Administração, Pontifícia Universidade Católica de Minas Gerais - Belo Horizonte MG, Brasil.E-mail: carvalhoneto@pucminas.br
\end{abstract}

\section{Betania Tanure}

Professora do Programa de Pós-Graduação em Administração, Pontifícia Universidade Católica de Minas Gerais - Belo Horizonte MG, Brasil. E-mail: betaniatanure@pucminas.br

\section{Carolina Maria Mota Santos}

Doutoranda do Programa de Pós-Graduação em Administração, Pontifícia Universidade Católica de Minas Gerais - Belo Horizonte MG, Brasil.E-mail: cmotasotnas@yahoo.com.br

\section{Gustavo Simão Lima}

Doutorando do Programa de Pós-Graduação em Administração, Pontifícia Universidade Católica de Minas Gerais - Belo Horizonte MG, Brasil.E-mail: gsimao@gmail.com

\section{Resumo}

O objetivo deste artigo é relacionar o tipo psicológico dos executivos que atuam no nível estratégico das grandes empresas com as características que a literatura aponta para o líder transformacional que, embora deificado, é o mais citado pela literatura atual. O referencial teórico apresenta uma síntese da literatura sobre liderança, desde a Teoria dos traços até a Teoria da liderança transformacional. Utiliza-se a ferramenta MBTI (Myers-BriggsTypeIndicator), um indicador de tipos psicológicos baseado no trabalho de Carl G. Jung. Uma pesquisa quantitativa com a amplitude da que originou este trabalho é rara mesmo na literatura internacional, utiliza-se uma amostra de 430 executivos. A pesquisa revela que existe mais divergência do que convergência entre as características encontradas nos executivos brasileiros $e$ as características dos líderes transformacionais. Os brasileiros apresentam dificuldade para perceber a necessidade de mudanças, enquanto os líderes transformacionais seriam mais aptos para conduzilas. Os executivos brasileiros são enérgicos e

\section{Abstract}

The goal of this article is to relate the psychological type of the executives who are in the strategic level of corporations in Brazil with the characteristics showed in the literature about transformational leadership. The last, although deified, is the most mentioned by the current literature. The theoretical framework presents a synthesis of the literature on leadership, from the 1960s to the Theory of transformational leadership. We used the MBTI (Myers-Briggs Type Indicator), an indicator of psychological types based on Carl G. Jung work. A quantitative research with the width of the one that originated this work is rare in literature; we applied the MBTI in a sample of 430 executives. The research reveals that exists more divergence than convergence among the characteristics found in Brazilian executives and the characteristics of transformational leadership. Brazilian leaders show difficulty to see the need for changes while transformational leaders are said to be more capable to lead people. Brazilian executives are hard and inflexible when the situation demands, unlike what the Theory of transformational leadership 
inflexíveis quando a situação exige, ao contrário do que apregoa a teoria da liderança transformacional, para a qual o líder deve ter consideração e respeito pelos liderados. A empatia e a preocupação com os liderados são características presentes entre os líderes transformacionais, mas não tão presente entre os brasileiros.

Palavras-chave: Executivos. Liderança. Teoria Transformacional.

\section{INTRODUÇÃO}

Embora a liderança seja foco de muitos estudos, não há muito consenso sobre o seu conceito, bem como sobre o comportamento e o estilo do que seja um "líder" (BURNS, 1978; BOWDITCH; BUONO, 2002). Esta área de pesquisa muitas vezes apresenta resultados inconclusivos e contraditórios (YULK et al. 1990). De toda forma, a Teoria Transformacional, dominante no mainstream norte-americano, absorve características de várias abordagens anteriores, chegando a uma ingênua caracterização do líder como um super-homem, com todas as qualidades possíveis e imaginárias para um mundo de "perfeitas" organizações. Esta deificação do líder é abordada amplamente na literatura, algo preditiva, sobre liderança.

Neste artigo, serão tratadas características do líder transformacional para compará-las com o resultado de ferramenta que indica o perfil psicológico dos líderes brasileiros (executivos que chegaram ao topo da carreira) não porque se assuma essa ingênua deificação do líder transformacional, mas sim porque a Teoria da liderança transformacional é atualmente a mais citada pela literatura, tanto de sua matriz norte-americana quanto dos autores brasileiros que trabalham com liderança dentro das organizações.

Entende-se por líder o executivo que alcançou o primeiro, o segundo e o terceiro escalão das grandes organizações brasileiras. A competição para chegar ao topo da hierarquia das maiores empresas é duríssima, o filtro é cada vez maior. Estudos mostram que o executivo na década de 1990 tinha uma possibilidade em 14.000 de chegar à presidência das maiores empresas brasileiras; nos anos 2000, esta possibilidade caiu de um para 180.000. (TANURE; CARVALHO NETO; ANDRADE, 2007) says. Empathy and concern with those who are led are characteristics of transformational leaders that are not so present among Brazilian leaders.

Key words: Executives. Leadership. Transformational Theory.

O referencial teórico deste artigo sintetiza a evolução sobre a temática da liderança a partir da abordagem da personalidade (teoria do grande homem e teoria dos traços) até chegar à abordagem da liderança transformacional. A partir dessa abordagem, busca-se relacionar as características esperadas do estilo de liderança transformacional, defendido por boa parte da literatura, com as características encontradas em pesquisa onde aplica-se a ferramenta MBTI, que indica as características dos líderes empresariais brasileiros por meio de seu perfil psicológico.

Associar liderança e a utilização de uma ferramenta usada pela área de Recursos Humanos no mundo inteiro em uma pesquisa tão vasta é raro mesmo na literatura internacional. O Myers-BriggsTypeIndicator, MBTI é um questionário baseado no trabalho de Carl G. Jung que busca compreender a personalidade. Amplamente empregado, apenas nos Estados Unidos é utilizado por mais de 2 milhões de pessoas. Foi preparado para se compreender a teoria de Jung sobre os tipos psicológicos. (MYERS, 1995; MYERS; MYERS, 1997; ROBBINS, 2002)

\section{Um SÉculo de Estudos SObre LIDERANÇA: DA ABORDAGEM DA PERSONALIDADE À TEORIA TRANSFORMACIONAL}

Neste tópico, discutiremos as principais vertentes teóricas da escola norte-americana de liderança. Começamos com a abordagem da personalidade, que foi marcada por duas teorias, a teoria do grande homem e a teoria dos traços. Em seguida, apresentaremos sinteticamente a abordagem comportamental. 
Seguem as abordagens situacional e contingencial. A vertente teórica denominada Nova Liderança compreende várias abordagens: a da liderança cultural; a da liderança Laissez Faire; a da liderança carismática; a da liderança visionária; a da liderança transacional; $e$, por fim, a abordagem da liderança transformacional. Dedicamos um tópico especial sobre a liderança transformacional por se tratar da mais influente no atual contexto de negócios.

\subsection{Abordagem da Personalidade}

A primeira sistematização dos estudos sobre liderança ocorreu durante o período das duas guerras mundiais e foi denominada de abordagem da personalidade, enfatizando as características pessoais do líder. Essa abordagem foi marcada por duas teorias, a teoria do grande homem (até a primeira guerra) e a teoria dos traços (entre as duas grandes guerras até o final da década de 1940). (SADLER, 2003)

De acordo com a teoria do grande homem, o líder era um indivíduo mais dotado do que as demais pessoas. Este era capaz de atrair seguidores por ter determinados atributos pessoais, como o carisma, a confiança que inspiram o respeito e a lealdade. Representavam um modelo de grande homem, um herói que todos admiravam (FIEDLER, 1981). Dessa forma, os estudos neste período partiam do pressuposto que havia elementos na história e na personalidade de grandes homens e mulheres dirigentes que os faziam ser líderes eficazes. A partir da compreensão da vida desses indivíduos poder-se-ia extrair os aspectos que os tornam líderes, imitá-los, e assim formar novos líderes eficazes. (SADLER, 2003)

A teoria dos traços surgiu entre as duas guerras mundiais. Os estudos passaram a focar os traços de liderança $e$ as maneiras como os indivíduos alçavam às posições de chefia, evoluindo com o tempo para questões relacionadas ao estudo das variáveis que tornariam os líderes eficazes. Nessa vertente o líder deveria possuir certas características especiais de personalidade que o permitiriam alçar e manter-se nos cargos de liderança, sendo entendido como um indivíduo diferente dos demais. (FIEDLER, 1981; BERGAMINI, 1994)

No final da década de 1940, a abordagem da personalidade passou por considerável declínio nos estudos sobre liderança. Nessa época surgiram questionamentos sobre a teoria dos traços e do grande homem e novas abordagens emergiram. Em relação ao grande homem, o principal questionamento referia-se à suposição de que quase todos os indivíduos são líderes em alguns grupos e liderados em outros. Assim, creditar apenas à personalidade o fator principal que leva o indivíduo a tornar-se líder não parecia coerente (STOGDILL, 1948). Em relação à teoria dos traços, o principal questionamento refere-se à pequena correlação entre as variáveis que mediriam traços e aptidões para o exercício da liderança (STOGDILL, 1948; FIEDLER, 1981).

Outro aspecto que mostra a fragilidade da abordagem da personalidade em relação ao entendimento da liderança é o seu viés genético. O indivíduo nasceria com atributos que o fazem ser um líder. Assim, ignora-se que um indivíduo possa aprender e adquirir novas características (MONTANA; CHARNOV, 1998). Essas fragilidades fizeram com que o foco dos estudos de liderança convergisse para o comportamento dos líderes. Em outras palavras, o foco alterou-se da seleção "natural" de líderes para o treinamento para a liderança (YULK; FLEET, 1994).

Passada a segunda grande guerra, a justificada aversão pelos horrores proporcionados pela visão nazista da supremacia racial, que pressupunha traços de personalidade e características biológicas de seres humanos "superiores", e também a aversão aos pogroms de extermínio de minorias e oponentes stalinistas, todos estes desastres conduzidos por "grandes homens" como Hitler e Stalin, também contribuíram para a forte crítica a estas teorias.

\subsection{Abordagem Comportamental}

No início da década de 1950 teve origem a abordagem comportamental, que tinha seu foco voltado à compreensão do que os dirigentes realmente fazem, centrando sua atenção nos tipos de comportamento adotados pelos líderes e quais destes comportamentos seriam mais eficientes para a organização (BLAKE; MOUTON, 1978).

Tal abordagem preconiza que a liderança pode ser aprendida sob forma de técnicas de desenvolvimento pessoal, modificando e adaptando comportamentos para formar líderes (YULK; FLEET, 1994; BOWDITCH; 
BUONO, 2002). Buscava-se, assim, examinar os padrões comportamentais típicos do líder no grupo e as diferenças de comportamento entre os líderes eficazes $e$ ineficazes. Nesse sentido, a principal indagação dos pesquisadores referia-se à compreensão de "como" $e$ "quais" seriam as melhores maneiras usadas pelos dirigentes, em termos de capacidade de orientar, motivar e reunir esforço de outros indivíduos para alcançar as metas da organização (BLAKE; MOUTON, 1978).

De modo geral, os estudos direcionados sob a abordagem comportamental se incumbiram de examinar as diferenças em padrões de comportamento entre líderes eficazes e ineficazes, bem como de correlacionar o comportamento do líder e os critérios de efetividade da liderança. Esses estudos realizados nos EUA mostraram-se contraditórios e inconclusivos, apesar de haver indícios positivos de correlação entre o comportamento do líder e a satisfação dos liderados (YULK et al. 1990). Esses estudos não foram capazes de evidenciar em aspectos detalhados quais seriam estes comportamentos "eficazes".

Para os críticos dessa abordagem, o líder não é eficaz apenas por ser capaz de ter um comportamento que o torne líder, a situação e a contingência são fatores também relevantes para se avaliar a liderança e a eficácia deste na organização. (FIEDLER, 1981)

\subsection{Abordagem Situacional e Contingencial}

Na esteira dessas críticas, no início de 1960 surgiram duas novas abordagens: a situacional e a contingencial. Para essas abordagens, os líderes eficazes são aqueles "[...] capazes de diagnosticar o seu meio ambiente e identificar as necessidades específicas de cada situação" (HERSEY; BLANCHARD, 1980, p. 4). Nesse sentido, um líder eficaz é aquele que compreende a dinâmica da situação que ele e seus subordinados estão envolvidos e consegue adaptar as suas habilidades a essa dinâmica, ou seja, o sucesso da liderança encontra-se na liderança adaptativa. (MONTANA; CHARNOV, 1998; BOWDITCH; BUONO, 2002)

A liderança situacional preconiza a avaliação da eficácia da liderança em termos de produtividade do grupo, ou seja, foca num contexto micro. Parte-se do princípio que o interesse das organizações é encontrar líderes capazes de aumentar a eficácia dos grupos que lideram.
Nesse sentido, a escolha de um indivíduo para exercer uma posição de liderança é determinada por fatores situacionais como os fatores físicos e geográficos e as características dos membros das organizações (LEAVITT, 1951; KIPNIS, 1957). As características dos membros são determinantes para a escolha do líder, pois em última análise são elas que selecionarão o líder.

Numa perspectiva mais macro, a abordagem contingencial preconiza que o líder de sucesso é aquele que consegue decodificar e analisar o contexto estrutural (ou exógeno) pelo qual a organização está passando. Por meio dos recursos de que dispõe, este líder deve ser capaz de criar soluções para se adaptar a estas demandas, às exigências da contingência. Nesse sentido, cabe ao líder, por exemplo, criar um ambiente no qual as pessoas possam demonstrar suas potencialidades e consigam se motivar serem responsáveis pelos resultados da organização. (ROBBINS, 2000)

Essas abordagens conferem um caráter multidimensional inexistente nas outras fases do estudo da liderança. Pela primeira vez o tema não foi considerado na forma unidimensional como nos casos anteriores (personalidade e comportamental). Nessa abordagem a liderança eficaz depende de um ou mais fatores referentes à personalidade, ao comportamento, à influência $e$ à situação. Foi a primeira tentativa de unir esforços para compreender a liderança como uma perspectiva associada às abordagens anteriores, com o intuito de utilizar todas as variáveis possíveis para se explicar o fenômeno. (FIEDLER, 1981; BERGAMINI, 1994)

Nesse sentido, a personalidade do líder proporciona, parcialmente, a chance de o indivíduo galgar uma posição de liderança e determina, de forma limitada, a maneira como ele se comportará nesse exercício, assim como sua chance de sucesso. É importante observar que não é isso, isoladamente, que indica o seu êxito como líder. Não é o agrupamento de muitos atributos e aptidões que determina se ele é o líder "ideal". O que mostrará isso, no caso da abordagem situacional, é a capacidade de o indivíduo reunir os atributos e aptidões que a situação exige (FIEDLER, 1981). No caso da abordagem contingencial, é a capacidade do indivíduo de compreender uma dinâmica estrutural, de mercado, e traduzir este entendimento em atitudes que melhor se adaptem a este contexto. (HERSEY; BLANCHARD, 1980) 


\subsection{A Abordagem da Nova Liderança}

A partir da década de 1980, surgiram diversos estudos com novas abordagens sobre o construto da liderança, apresentando em comum a ideia que o líder deveria utilizar uma visão articulada da organização associada a seus valores. Assim, o líder deixa de assumir um papel dedicado principalmente a influenciar o processo para desenvolver o papel de gestor de significados. Isso porque a liderança não é um fenômeno unidirecional do líder para o liderado; o processo ocorre em duplo sentido e depende tanto do líder quanto do liderado para que os objetivos $e$ expectativas mútuas sejam cumpridos. Nesse sentido, a visão significa a capacidade do líder de entender e agir considerando a síntese dos desejos e crenças compartilhadas pelo grupo. Essa visão, a habilidade de apreender e ordenar o significado da realidade e suas ressonâncias no imaginário coletivo é o que confere ao líder a sua força perante o grupo e garante o exercício legítimo da sua influência. (HOLLANDER, 1978)

Estudos que apresentam essas características, sob abordagens diferentes, foram agrupados numa perspectiva mais ampla denominada abordagem da Nova Liderança. A Nova Liderança é composta pela: abordagem da liderança cultural (Schein, 1985; Alveson, 1992); abordagem da liderança Laissez Faire, (Burns, 1975; Bass e Avolio, 1995); abordagem da liderança carismática (Stoner e Freeman, 1999; Conger, 1991); abordagem da liderança visionária (Westley e Mintzberg, 1989); abordagem da liderança transacional (Bass, 1985; Bass e Avolio, 1990); e, por fim, a abordagem da liderança transformacional (Tichy e Devana, 1986; Bass e Avolio, 1990). Cada uma dessas abordagens será apresentada sucintamente a seguir, pois nosso foco é a liderança transformacional, para qual converge a maior parte da literatura sobre liderança, majoritariamente de origem norte-americana.

A abordagem da liderança cultural pressupõe que o papel fundamental do líder é reconhecer a necessidade de mudança cultural, trazendo a partir daí as mudanças necessárias para a organização (SCHEIN, 1985). A abordagem da liderança Laissez Faire é caracterizada pela falta de envolvimento do líder nos problemas organizacionais. Esse tipo de líder prefere manter-se o máximo possível afastado de seus liderados, ofertando pouca ou nenhuma orientação. Essa abordagem segue como uma resposta à tendência das teorias de novas lideranças que surgiram na década de 1980 e 1990, de focarem o líder sob três aspectos principais: a imagem do líder heroico; a liderança vista apenas nos altos escalões e; foco nos indivíduos e não nas equipes. Nesse sentido, a liderança Laissez Faire tornou-se uma alternativa que visava substituir a imagem do líder como herói visionário para focar na condução das pessoas a se liderarem, sendo instigadas a se tornarem líderes delas mesmas. Isto se relaciona com a capacidade de desenvolver o espírito de liderança dos subordinados, com o intuito de torná-los independentes, construtores de seus próprios talentos e motivações. (SIMS; LORENZI, 1992; BASS; AVOLIO, 1995)

Stoner e Freeman (1999) definem o líder carismático como o indivíduo que consegue atrair, motivar e satisfazer parte dos seus liderados a ponto deles efetuarem suas tarefas pelo fato de terem empatia pelo líder. No caso da abordagem visionária, a liderança vai além do carisma, necessita de capacidade de criar e estabelecer uma visão do futuro muito mais realista e atraente, capaz de gerar credibilidade e traduzir as aspirações e a confiança do liderado. (ROBBINS, 2000)

A abordagem da Liderança transacional é caracterizada como um processo de troca entre líderes e liderados. Essa liderança articula-se através de recompensas por meio das quais os líderes conseguem captar os desejos dos seus liderados, como salários, promoção e melhoria da satisfação profissional. O líder se esforça para satisfazer tais desejos; em troca, os liderados devem cumprir determinados objetivos, sendo premiados de acordo com a performance. O papel do líder passa a ser o de verificar a execução do acordo feito com o liderado e intervir quando surgem desvios em relação ao combinado, quando a tarefa acordada não está ocorrendo como planejada (BASS, 1985; BASS; AVOLIO, 1990; NORTHOUSE, 2001).

Burns (1978) e Kirkbride (2006) vão mais além e caracterizam a liderança transacional não apenas como transações de troca de natureza econômica, como também de troca de natureza política e psicológica entre líderes e liderados para alcançar o sucesso (recompensa contingencial).

Geralmente, os líderes transacionais são eficientes, conseguem manter a produtividade organizacional. Esse tipo de liderança manifesta-se com mais frequência em organizações com estruturas formais e rígidas em que a expectativa gravita em torno do cumprimento 
da meta preestabelecida. Uma vez atingida esta meta, o indivíduo recebe sua recompensa, acordada com o líder anteriormente. A principal crítica a esta abordagem é a de que se a meta foi alcançada o liderado não se sente incentivado a realizar tarefas que estejam acima das expectativas acordadas, mesmo que isso seja possível, pois o acordo entre o que ele espera receber já foi atendido. (BASS; AVOLIO, 1993)

\subsubsection{Abordagem da Liderança Transformacional}

O principal objetivo da liderança transformacional é proporcionar ao liderado um ambiente organizacional harmonioso, no qual ele possa desenvolver seu potencial, incentivando a melhoria de sua performance. Esse tipo de liderança procura aumentar a consciência do grupo por meio do estímulo ao crescimento individual, buscando alinhar mais as expectativas individuais $e$ organizacionais (BASS, 1985). Quando preciso, o líder transformacional causa mudanças internas e externas por meio da implementação de uma visão do futuro capaz de gerar credibilidade e traduzir as aspirações e a confiança dos liderados. (AVOLIO et al. 1991)

Os primeiros estudos sobre liderança transformacional verificaram a existência deste estilo de liderança apenas entre os níveis mais altos das organizações e principalmente entre as empresas que buscavam líderes aptos para conduzir mudanças (TICHY; DEVANNA, 1986; AVOLIO et al. 1991). O objeto deste estudo, executivos situados nos níveis mais altos das grandes empresas brasileiras, é verificar se há características dos líderes transformacionais, exatamente neste nível salientado por Avolio et al. (1991).

A liderança transformacional é definida como um processo de solicitação do empenho dos liderados num contexto de partilha de valores e de visão. $\mathrm{Na}$ concepção de Bass e Avolio (1994), líderes transformacionais possuem quatro características essenciais. A primeira é a consideração individualizada, a atenção às necessidades de cada liderado. $\mathrm{O}$ cuidado em termos de potencialidade e de desenvolvimento inclui delegar, coaching, crítica construtiva e feedback. Tais líderes conhecem bem seus liderados e ouvem suas preocupações e ideias, reconhecem as diferenças entre as pessoas, suas forças e fraquezas, gostos e desagrados. Ele é um ouvinte "ativo", que participa do processo de formação de opinião dos liderados, incentiva intercâmbio de pontos de vista em dois sentidos e promove o autodesenvolvimento.

A segunda característica essencial dos líderes transformacionais é denominada estímulo intelectual. O líder consegue expor diferentes razões e caminhos para que os liderados reconsiderem e mudem a maneira de pensar e enfrentar os problemas técnicos e humanos da organização, favorecendo o liderado a se autoconhecer, a questionar suas crenças e valores de forma a aumentar o seu nível de criatividade e a conviver com novos elementos.

A terceira característica dos líderes transformacionais é a inspiração motivacional, entendida como a aptidão do líder para constituir uma visão e comunicá-la de forma entusiasmada aos liderados, inspirando-os a encontrar novas possibilidades. A inspiração motivacional resulta da capacidade pessoal do líder, é inata, sendo assim, impossível de desenvolver. Esses líderes tendem a ser capazes de articular, de uma forma emocionante e atraente, uma visão de futuro que os seguidores são capazes de aceitar. (AVOLIO et al. 1991)

A quarta característica dos líderes transformacionais é a empatia. Os líderes transformacionais devem mostrar respeito pelos outros e construir uma relação de confiança, desenvolvendo uma referência de poder e influência sobre seus seguidores, os estimulando a alcançar níveis mais altos de desempenho. Esses líderes são considerados como um modelo, quer porque eles apresentam algumas características pessoais ou porque demonstram comportamentos morais a serem imitados. Tais líderes são vistos frequentemente como tendo elevado conceito de moralidade, confiança, integridade, honestidade e finalidade. Demonstram competência acima do comum, comemoram as realizações de seus seguidores e usam o poder para ganhos coletivos. (AVOLIO et al. 1991)

Tichy e Devanna (1986) identificaram outros elementos sobre o comportamento dos líderes transformacionais como agentes de mudança. Eles são designados para transformar a organização pela qual são responsáveis e demonstram coragem para isso. Eles podem lidar com a resistência, tomar uma posição, assumir riscos e confrontar realidade. Eles veem o erro como possibilidade de aprendizado, e o fazem por causa da complexidade e da incerteza mostrando-se como visionários. (TICHY; DEVANNA, 1986) 
Nessa abordagem, o líder transformacional prepara os liderados a executarem tarefas acima de suas expectativas, trabalhando objetivos coletivos ao invés de interesses pessoais imediatos (BASS, 1985). O atual foco da literatura na liderança transformacional situa-se no contexto das mudanças contemporâneas no ambiente de negócios, como o fato de as organizações terem se tornado, até certo ponto, menos hierárquicas e mais flexíveis, mais orientadas para o trabalho em equipe. (ROSENER, 1995)

\section{A Ferramenta MBti para Analisar o TIPo Psicológico dos Executivos}

O Myers-Briggs TypeIndicator (MBTI), é um questionário, baseado no trabalho de Carl G. Jung. O MBTI analisa as personalidades por meio da observação de oito preferências básicas, que são pares opostos: (extroversão $\mathrm{x}$ introversão; sensação $\mathrm{x}$ intuição; pensamento $\mathrm{x}$ sentimento; julgamento $\mathrm{x}$ percepção) utilizadas pelas pessoas em diferentes momentos. (MYERS, 1995)

Apenas nos Estados Unidos mais de 2 milhões de pessoas utilizam o questionário do MBTI. Entre as empresas que utilizam esse instrumento estão a Apple Computer, a AT\&T, a Citicorp, a Exxon, a GE, a 3M, além de diversos hospitais e instituições de ensino. (ROBBINS, 2002)

O tipo psicológico é determinado pelas quatro preferências (motivação, observação, decisão e modo de vida) "escolhidas" ao responder às perguntas do MBTI (Quadro 1). Como cada uma das oito preferências pode ser por uma letra (E -extroversion, $\mathrm{I}$-introversion, $\mathrm{S}$-sensing, $\mathrm{N}$-intuition, $\mathrm{T}$-thinking, $\mathrm{F}$ - feeling, $\mathrm{J}$-judging ou $\mathrm{P}$-perceiving), um código de quatro letras é utilizado para indicar o tipo psicológico. A combinação das quatro escalas de preferência resulta em 16 tipos psicológicos. (MYERS, 1995)
A Motivação refere-se ao ponto em que a pessoa prefere concentrar sua atenção. Há a escala EI, ou seja, E de extroversão e I de introversão. Pessoas que preferem a Extroversão costumam focalizar o mundo externo das pessoas e os eventos. A atenção parece fluir para os objetivos e as pessoas do ambiente onde o indivíduo está. Pessoas que preferem a Introversão costumam focalizar sua atenção em seu próprio mundo interior de ideias e de experiências. Nesse caso, o principal interesse está no mundo interior de conceitos e de ideias. (MYERS, 1995; MYERS; MCCAULLEY, 1985)

A Observação é realizada para obter informações sobre algo. Neste item temos a Escala SN, ou seja, Sensação e Intuição. As pessoas que preferem a Sensação gostam de obter informações por meio dos cinco sentidos. Elas observam o que está acontecendo ao redor e têm facilidade para reconhecer a realidade prática de uma situação. São, por natureza, amantes dos prazeres e, amando a vida como ela é e tendo grande capacidade de fruição, estão, em geral, contentes. Preferem a arte de viver no presente, as satisfações de empreendimento e aquisição. Já as pessoas que preferem a Intuição gostam de obter informações observando o todo, focalizando as relações e conexões entre os fatos. São por natureza iniciadores, inventores e promotores e apresentam pouca capacidade de viver a vida e desfrutar o presente. Desejando oportunidades e possibilidades e sendo muito imaginativos, são inventivos e originais, bem indiferentes ao que os outros têm e fazem. (MYERS, 1980; 1995)

A Decisão, como o próprio nome já diz, é como se tomam decisões. Aqui a escala é TF que nos diz do pensamento e do sentimento. As pessoas que preferem o Pensamento para tomar decisões costumam observar as consequências lógicas de uma escolha ou ação. Preferem organizar e estruturar as informações para tomar decisões de maneira lógica e objetiva. Valorizam a lógica mais do que o sentimento. São pessoas mais

\begin{tabular}{|c|c|c|c|c|c|c|c|}
\hline \multicolumn{2}{|c|}{$\begin{array}{l}\text { Motivação } \\
\text { COMO vOCÊ SE } \\
\text { REENERGIZA }\end{array}$} & \multicolumn{2}{|c|}{$\begin{array}{l}\text { OBSERVAÇÃo } \\
\text { COMO SE OBTEM } \\
\text { INFORMAÇÃo }\end{array}$} & \multicolumn{2}{|c|}{$\begin{array}{c}\text { Decisão Como SE TOMA } \\
\text { DECISÃo }\end{array}$} & \multicolumn{2}{|c|}{$\begin{array}{l}\text { MOdO DE VIDA COMO SE } \\
\text { ORIENTA EM RELAÇÃO AO } \\
\text { MUNDO EXTERIOR }\end{array}$} \\
\hline$E$ & I & S & $\mathrm{N}$ & $\mathrm{T}$ & $\mathrm{F}$ & $\mathrm{J}$ & $\mathrm{P}$ \\
\hline Extroversão & Introversão & Sensação & Intuição & Pensamento & Sentimento & Julgamento & Percepção \\
\hline
\end{tabular}

Quadro 1: As quatro preferências do MBTI

Fonte: Adaptado de Myers (1995) 
interessadas em coisas do que em relações humanas. Naturalmente breves, parecem às vezes sem amizades e socialmente sem interesse por isso. São mais fortes em habilidades executivas do que nos processos de socialização. Já as pessoas que preferem o Sentimento para tomar decisões levam em consideração aquilo que é importante para elas e para as outras pessoas, têm maior capacidade de empatia. Preferem organizar e estruturar as informações para tomar decisões de maneira pessoal e orientada para os valores. São mais interessadas nas pessoas do que nas coisas. São mais fortes na socialização do que em habilidades executivas. (MYERS, 1980; 1995)

Em relação ao Modo de vida, ou seja, como as pessoas se orientam em relação ao mundo exterior, temos a escala JP, que significa julgamento e percepção. As pessoas que preferem utilizar o processo de Julgamento costumam viver de maneira planejada e metódica, buscando controlar a vida. Além disso, parecem ser organizadas, com propósitos e decisivas. Já as pessoas que preferem utilizar o processo de Percepção costumam viver de maneira bastante flexível e espontânea, procurando experimentar e compreender a vida, em vez de controlá-la. São curiosas e adaptáveis, abertas a novos acontecimentos e mudanças. (MYERS, 1995; MYERS; MCCAULLEY, 1985)

No quadro a seguir estão retratados os 16 tipos psicológicos resultantes da combinação das quatro escalas de preferência. Posteriormente serão detalhados apenas os tipos psicológicos mais evidenciados entre os executivos brasileiros (ESTJ; ENTJ e ISTJ), que é o foco deste artigo.

\begin{tabular}{|c|c|c|c|c|c|}
\hline \multirow{2}{*}{ I } & $\mathbf{S}$ & $\mathbf{S}$ & $\mathbf{N}$ & $\mathbf{N}$ & \multirow{2}{*}{ c } \\
\hline & ISTJ & ISFJ & INFJ & INTJ & \\
\hline \multirow{4}{*}{ E } & ISTP & ISFP & INFP & INTP & \multirow{3}{*}{$\mathbf{P}$} \\
\hline & ESTP & ESFP & ENFP & ENTP & \\
\hline & ESTJ & ESFJ & ENFJ & ENTJ & \\
\hline & $\mathbf{T}$ & $\mathbf{F}$ & $\mathbf{F}$ & $T$ & \\
\hline
\end{tabular}

Quadro 2: Efeitos das combinações

Fonte: Myers (1995)
Os indivíduos ESTJ apresentam como ponto forte o interesse por organização de projetos, operações, procedimentos e pessoas, para então agir e executar as tarefas. Valorizam a competência, a eficiência e os resultados. Resolvem os problemas de maneira objetiva e são bastante duros quando a situação exige. Terminam passo a passo aquilo que foi começado, porém podem decidir muito rapidamente. Agem como líderes tradicionais que respeitam bastante a hierarquia. São pessoas que assumem o comando rapidamente e adaptam experiências passadas à solução de problemas, mas geralmente não enxergam a necessidade de mudanças (MYERS, 1995; HIRSH, KUMMEROW, 1995)

Os ENTJ são pessoas lógicas, objetivas e determinadas quanto àquilo que acham que é conceitualmente válido. Entretanto, geralmente ignoram as necessidades alheias quando concentrados em uma tarefa. Criam estratégias que funcionam na direção de objetivos amplos. Lidam diretamente com os problemas causados por confusão e ineficiência. São bons organizadores e líderes por natureza. Adotam uma abordagem energética, orientada para a ação. Gerenciam diretamente e são duros quando necessário, mas podem tomar decisões muito rapidamente e parecer impacientes e dominadores. (MYERS, 1995; HIRSH; KUMMEROW, 1995)

Os ISTJ são pessoas meticulosas, cuidadosas, sistemáticas, responsáveis e cautelosas com detalhes. Realizam tarefas rapidamente e dentro do prazo, mas podem ignorar implicações de longo prazo para favorecer as operações diárias e se recusam a fazer aquilo que não faz sentido para eles. Em relação à liderança, utilizam a experiência e o conhecimento dos fatos para tomar decisões, entretanto podem ser indelicados com as pessoas, além de rígidos e inflexíveis. Respeitam abordagens tradicionais e hierárquicas além de prestar atenção às necessidades imediatas e práticas da organização. Apresentam como ponto forte um grande senso de responsabilidade e são pessoas muito leais às organizações. Geralmente prefere trabalhar sozinho (MYERS, 1995; HIRSH; KUMMEROW, 1995). O Quadro 3 a seguir demonstra as principais características destes três tipos predominantes. 


\begin{tabular}{|c|c|}
\hline Tipo Psicológico & CaRActerísticas \\
\hline ESTJ & $\begin{array}{l}\text { 1. Facilidade para liderar; } \\
\text { 2. Capacidade de assumir o comando rapidamente; } \\
\text { 3. Resolvem os problemas de maneira objetiva; } \\
\text { 4. São enérgicos quando a situação exige; } \\
\text { 5. Podem não enxergar a necessidade de mudanças; }\end{array}$ \\
\hline ENTJ & $\begin{array}{l}\text { 1. Lógicos, objetivos, críticos; determinados quanto àquilo que acham que é válido; } \\
\text { 2. Gerenciam de forma direta; } \\
\text { 3. São enérgicos quando a situação exige; } \\
\text { 4. São bons organizadores e líderes por natureza; } \\
\text { 5. Criam estratégias que funcionam na direção de objetivos amplos; } \\
\text { 6. Podem tomar decisões rapidamente e parecer impacientes e dominadores; }\end{array}$ \\
\hline ISTJ & $\begin{array}{l}\text { 1. Pessoas cuidadosas, sistemáticas, meticulosas, responsáveis e cautelosas; } \\
\text { 2. Habilidosas com detalhes e cuidadosas ao gerenciá-los; } \\
\text { 3. Utilizam a experiência e o conhecimento dos fatos para tomar decisões; } \\
\text { 4. Podem ignorar implicações de longo prazo para favorecer operações diárias e se recusar a } \\
\text { fazer aquilo que não faz sentido para eles; e } \\
\text { 5. Podem ser indelicados com as pessoas, além de rígidos e inflexíveis. }\end{array}$ \\
\hline
\end{tabular}

Quadro 3: Tipo psicológico

Fonte: Adaptado de Myers (1995) e Hirsh e Kummerow (1995)

\section{Considerações Metodológicas}

Este artigo baseia-se em pesquisa de caráter descritivo, realizada com executivos brasileiros de nível estratégico. Por nível estratégico se entende presidentes, vice-presidentes, diretores e executivos de terceiro nível (logo abaixo de vice-presidentes e diretores).

Mattar (1999) ressalta que a pesquisa descritiva caracteriza-se por ter objetivos bem definidos, procedimentos formais estudados e orientados para a solução de problemas ou avaliação de alternativas de cursos de ação. Além disso, ela é utilizada quando o propósito for:

a) descrever as características de grupos;

b) estimar a proporção de elementos numa população específica que tenham determinadas características ou comportamentos; $e$

c) descobrir ou verificar a existência de relação entre variáveis.

Portanto, a estratégia de pesquisa recaiu sobre a pesquisa descritiva, já que o objetivo é relacionar o tipo psicológico dos executivos no nível estratégico das grandes empresas brasileiras com as características que a literatura aponta para o líder transformacional.

O MBTI tem oito variáveis (E, I, S, N, F, T, P, J), que formam 16 tipos psicológicos, combinações dessas oito variáveis. O universo da amostra foi constituído por executivos das 500 maiores empresas situadas no Brasil. A ferramenta MBTI foi aplicada em 430 executivos de nível estratégico de 344 dentre estas empresas.

Como estratégia, foi, portanto, desenvolvida uma pesquisa quantitativa. Justifica-se a escolha da abordagem quantitativa tendo-se em vista a extensão geográfica, o grande número de respondentes e variáveis, a intenção de obter dados estatísticos e de generalização dos resultados.

Os dados quantitativos foram coletados por meio de um questionário disponibilizado via internet e também impresso para executivos de empresas de grande porte que operam no Brasil, dentre as 500 maiores empresas. Em relação à atividade das empresas, $47,5 \%$ dos executivos entrevistados atuam em indústria, 17,5\% em empresas de telecomunicações, $13,1 \%$ em serviços, $12,1 \%$ em bancos/serviços financeiros, $7,8 \%$ no serviço público e $2,1 \%$ no comércio. Foram recebidos 965 questionários preenchidos por executivos (presidentes, vice-presidentes/diretores e gerentes de terceiro nível) de 344 grandes empresas. Destes, 965 questionários, 36 foram de presidentes, 12 de vice-presidentes, 209 de diretores e 708 de gerentes de terceiro nível. A maior parte dos entrevistados $(85,1 \%)$ tem entre 31 e 50 anos, com destaque para 
a idade de 31 a 40 anos, que representa $45,2 \%$ da amostra de acordo com a tabela a seguir.

Tabela 1: Idade dos executivos

\begin{tabular}{|l|c|c|}
\multicolumn{1}{|c|}{ Idade } & FrequênCIA & $\begin{array}{c}\text { PerCentagem } \\
\text { VÁlidA }\end{array}$ \\
\hline Até 30 anos & 59 & 6,2 \\
\hline 31 a 40 anos & 433 & 45,2 \\
\hline De 41 a 50 anos & 383 & 39,9 \\
\hline Acima de 51 anos & 84 & 8,8 \\
\hline Total & 959 & 100, \\
\hline Não respondeu & 6 & \\
\hline
\end{tabular}

Fonte: Dados da pesquisa

Mais de um terço dos entrevistados (35\%) trabalha há menos de cinco anos na empresa, contudo há uma boa quantidade de pessoas que trabalha há mais de 16 anos na empresa (28\%). Quase metade dos entrevistados está há dois anos ou menos no cargo atual, e $82 \%$ estão há cinco anos ou menos. As mulheres são minoria, principalmente no cargo de presidência, passando de 5,6\% na presidência para $25,1 \%$ na gerência de terceiro escalão, abaixo da diretoria.

O questionário aplicado aos executivos é constituído por questões fechadas e utilizou algumas questões de múltipla escolha e outras em escala tipo Likert. $\mathrm{O}$ uso da escala tipo Likert de 1 a 7 possibilitou a obtenção de uma graduação quantificada das percepções dos entrevistados, permitindo, assim, o cálculo de índices de cada uma delas.

Considerando-se a metodologia proposta, o número de variáveis e o tamanho da amostra, utilizaram-se as ferramentas estatísticas descritas abaixo, para proceder-se ao tratamento dos dados.

O Teste Qui-Quadrado avalia a associação (não necessariamente linear) entre duas variáveis categóricas, em que, pelo menos, uma delas não é ordinal. Essa comparação é feita por meio de uma estatística que compara os valores observados em cada categoria com os valores esperados (estimados), e, uma vez que o "p" - valor desta estatística - é menor ou igual a 0,05, diz-se existir uma associação estatisticamente significativa entre as variáveis em questão. (1) $\mathrm{H}_{\mathrm{o}}$ : As variáveis em estudos são independentes. (2) $\mathrm{H}_{1}$ :
As variáveis em estudo não são independentes, ou seja, apresentam alguma associação.

A análise de variância, ANOVA (a um fator), é uma técnica usada para testar a igualdade de três ou mais médias, ao mesmo tempo, provenientes de amostras independentes. ANOVA a um fator significa dizer que a característica - fator - que diferencia cada amostra é o mesmo. Por exemplo, no caso da comparação entre cargos, o fator que diferencia uma amostra da outra é o cargo dos indivíduos. A comparação entre as amostras é feita por meio de uma estatística de teste que avalia basicamente a variação entre as amostras, e quanto maior essa variabilidade, maior a evidência contra a hipótese de igualdade das médias. Assim sendo, quando o "p" - valor dessa estatística - é menor do que 0,05, afirma-se que existe alguma diferença entre as médias avaliadas. No entanto, esse teste não aponta somente onde se encontra essa diferença. Para tal, usou-se o método de comparações múltiplas (método de Duncan), que retoma quais amostras apresentaram diferença significativa em relação às demais (comparadas duas a duas).

A Análise Fatorial é usada quando se tem um número grande de variáveis, como no caso deste estudo, e deseja-se agrupá-las em um número menor, a fim de facilitar o estudo. Nessa análise, a informação contida em p variáveis é substituída pela informação resumida por $\mathrm{k}$ variáveis, onde $\mathrm{k}<\mathrm{p}$. Essas novas $\mathrm{k}$ variáveis são chamadas de fatores e podem ser utilizadas em outras análises estatísticas, como análise de variância ou regressão.

\section{Apresentação e Análise dos Resultados}

Em relação ao resultado da aplicação do questionário do MBTI, os dados revelam que, em primeiro lugar, estão os executivos que apresentaram o tipo ESTJ (21,6\%). Em segundo lugar estão os executivos que apresentaram o tipo ENTJ (14\%) e, em terceiro lugar, logo em seguida os resultados apontam os executivos de alto escalão que apresentaram o tipo ISTJ $(13,5 \%)$, conforme Tabela 2 a seguir. 
Tabela 2: Resultado da aplicação da ferramenta MBTI nos executivos de alto escalão das grandes empresas brasileiras

\begin{tabular}{|c|c|c|c|}
\hline $\begin{array}{c}\text { Resultado } \\
\text { MBTI }\end{array}$ & FREQUÊNCIA & $\begin{array}{c}\text { PoRCEN- } \\
\text { TAGEM }\end{array}$ & $\begin{array}{c}\text { PERCEN- } \\
\text { TAGEM } \\
\text { VÁLIDA }\end{array}$ \\
\hline ESTJ & 93 & 9,6 & 21,6 \\
\hline ENTJ & 60 & 6,2 & 14 \\
\hline ISTJ & 58 & 6 & 13,5 \\
\hline INTJ & 41 & 4,2 & 9,5 \\
\hline ESTP & 39 & 4 & 9,1 \\
\hline ENTP & 32 & 3,3 & 7,4 \\
\hline INTP & 16 & 1,7 & 3,7 \\
\hline ISTP & 16 & 1,7 & 3,7 \\
\hline ENFP & 14 & 1,5 & 3,3 \\
\hline ESFJ & 13 & 1,3 & 3 \\
\hline INFJ & 13 & 1,3 & 3 \\
\hline ENFJ & 11 & 1,1 & 2,6 \\
\hline ISFJ & 9 & ,9 & 2,1 \\
\hline ESFP & 7 &, 7 & 1,6 \\
\hline INFP & 6 & ,6 & 1,4 \\
\hline ISFP & 2 & ,2 &, 5 \\
\hline Total & 430 & 44,6 & 100 \\
\hline $\begin{array}{l}\text { Não possui } \\
\text { MBTI }\end{array}$ & 535 & 55,4 & \\
\hline Total & 965 & 100 & \\
\hline
\end{tabular}

Fonte: Dados da pesquisa

Os tipos psicológicos que aparecem com maior frequência entre os executivos brasileiros que alcançaram o topo da hierarquia das grandes empresas possuem como característica principal a facilidade para liderar e assumir o comando rapidamente. A objetividade é também importante para esses dois tipos psicológicos (ESTJ e ENTJ), característica que pode ser relacionada com a eficiência salientada pela literatura dos líderes transformacionais.

Outro dado da pesquisa que corrobora alguns aspectos da teoria sobre liderança transformacional é que geralmente a existência do líder transformacional ocorre nos níveis mais altos das organizações, principalmente nas organizações que buscam líderes aptos para conduzir mudanças, situação bastante comum para as empresas nestes tempos de constantes fusões, aquisições e turbulências de mercado. Entretanto, os líderes transformacionais consideram-se agentes de mudança e, no caso do ESTJ, tipo mais encontrado entre os executivos brasileiros, apesar de estes apresentarem boa capacidade de assumirem o comando rapidamente, podem não enxergar a necessidade de mudanças.

Outra divergência entre as características do líder transformacional e as características dos tipos psicológicos dos executivos brasileiros sugeridos pela aplicação do MBTI é a existência de aspectos relacionados ao estereótipo feminino como a empatia e a preocupação com os liderados. O líder transformacional denota ser uma pessoa atenta às necessidades do seu grupo, conforme mostra o Quadro 4. Esse dado diverge principalmente do segundo e do terceiro tipos encontrados entre os executivos brasileiros, o ENTJ e o ISTJ. No caso do ENTJ, por serem pessoas que podem ignorar as necessidades alheias quando concentrados em uma tarefa. No caso do ISTJ, por serem indelicados, rígidos e inflexíveis; além disso, preferem trabalhar sozinhos.

Percebe-se que as características evidentes nos três tipos psicológicos (ESTJ; ENTJ; ISTJ) mais encontrados entre os executivos brasileiros são diferentes dos quatro blocos de características essenciais do líder transformacional, como visto no referencial teórico (atenção às necessidades dos liderados; estímulo intelectual; inspiração motivacional; empatia). Além da característica relacionada à atenção das necessidades do grupo de liderados e consideração com eles, o líder transformacional apresenta inspiração motivacional, entendida como uma capacidade de articular de maneira atraente uma "visão de futuro" que os liderados seriam capazes de aceitar e seguir. Entretanto, pelo menos no Brasil, existe uma realidade contrária a isso. Além de essa habilidade ser nata, segundo Avolio et al. (1991), ou seja, não tem como ser desenvolvida, como querer que um executivo racional demais atraia e emocione seus liderados? 


\begin{tabular}{|c|c|}
\hline $\begin{array}{l}\text { CARACTERÍSTICAS RELEVANTES DOS DOIS TIPOS PSICO- } \\
\text { LÓGICOS MAIS EVIDENTES DOS EXECUTIVOS BRASILEIROS }\end{array}$ & $\begin{array}{c}\text { CARACTERÍSTICAS SALIENTADAS PELA LITERATURA } \\
\text { SOBRE O LÍDER TRANSFORMACIONAL }\end{array}$ \\
\hline Objetivos, lógicos & Eficientes \\
\hline Facilidade para liderar & Buscam um ambiente harmonioso \\
\hline Enérgicos quando necessário & Apto para conduzir mudanças \\
\hline Críticos e determinados & Atento às necessidades individuais \\
\hline \multirow[t]{3}{*}{ Organizadores } & Estimulam o lado intelectual de seus liderados \\
\hline & Inspiração motivacional \\
\hline & Empatia \\
\hline
\end{tabular}

Quadro 4: Características do perfil psicológico dos executivos brasileiros por meio do MBTI versus características salientadas pela literatura sobre o líder transformacional

Fonte: Elaborado pelos autores

Comparando o tipo que mais se sobressaiu (ESTJ) e o tipo que está em terceiro lugar (ISTJ), é possível perceber que a única diferença ocorre em relação à preferência pela letra $\mathrm{E}$ - extroversão ou $\mathrm{I}$ - introversão. As pessoas que preferem a letra $\mathrm{E}$ costumam ter sua atenção focalizada nos objetivos e pessoas do meio ambiente. Já as pessoas que dão preferência para a introversão, focalizam a atenção em seu próprio mundo interior de ideias e experiências.

Já a diferença entre os tipos ESTJ, que mais se sobressaiu e ENTJ, tipo que está em segundo lugar, é que o primeiro utiliza a preferência $S$ - sensação. As pessoas deste tipo preferem obter informações através dos cinco sentidos. O tipo ENTJ utiliza a preferência $\mathrm{N}$ - Intuição. As pessoas do tipo N preferem obter informações por meio da observação do todo, focalizando as relações e conexões entre os fatos.

Avaliando-se os pares de letras predominantes, os dados indicam que o par TJ aparece nos três primeiros tipos da Tabela 2 (ESTJ, ISTJ e ENTJ). Ou seja, 49,1\% dos executivos brasileiros são $\mathrm{TJ}$.

Logo, os resultados apontam que os executivos de alto escalão das organizações brasileiras têm a preferência por características de comportamentos mais objetivos, racionais e planejados, de acordo com o Quadro 5. Ou seja, mais uma vez esses dados sugerem que o executivo que chega ao topo das grandes empresas brasileiras é essencialmente racional e menos flexível. Essas características divergem do modelo de liderança transformacional em que as habilidades comportamentais, mais relacionadas ao lado emocional (valores, percepção), são também bastante valorizadas.

\begin{tabular}{|l|l|}
\hline T Pensamento & $\begin{array}{l}\text { Preferem decidir organizando } \\
\text { e estruturando logicamente } \\
\text { (objetividade) }\end{array}$ \\
\hline F Sentimento & $\begin{array}{l}\text { Preferem decidir levando em } \\
\text { consideração o que é pessoal (valores) }\end{array}$ \\
\hline J Julgamento & $\begin{array}{l}\text { Preferem viver de forma planejada e } \\
\text { organizada }\end{array}$ \\
\hline P Percepção & $\begin{array}{l}\text { Preferem viver de forma flexível e } \\
\text { espontânea. }\end{array}$ \\
\hline
\end{tabular}

Quadro 5: Pares de letras que representam as principais características do MBTI

Fonte: Myers (1995)

Em relação ao MBTI completamente desmembrado em quatro letras, como se pode depreender somando as parcelas na Tabela 1, o que é explicitado na Tabela 2 a seguir, há predomínio da preferência E - extroversão $(62,6 \%)$ sobre a I - introversão $(37,4$ $\%)$. Percebe-se, portanto, que os executivos de alto escalão brasileiros preferem usar a energia do mundo exterior. Demonstram maior interesse pelas pessoas e eventos externos. Os extrovertidos apresentam atitude confiante e seu interesse e sua atenção segue acontecimentos objetivos, principalmente os do ambiente imediato. São pessoas de ação, governadas por condições objetivas. Autoconfiança, objetividade, assertividade e visão prática são o que mais se encontra nas empresas, e o que acaba por ser até mesmo mais valorizado, talvez até induzido pelo jogo de poder, pelo teatro organizacional e pela dinâmica imediatista das organizações atualmente. 
Tabela 3: MBTI Desmembrado

\begin{tabular}{|l|l|c|c|}
\hline & ClassificAÇão & FrEQUÊNCIA & $\begin{array}{c}\text { \% DE } \\
\text { ENTREVIS- } \\
\text { TADOS }\end{array}$ \\
\hline E & Extroversão & $\mathbf{2 6 9}$ & $\mathbf{6 2 , 6}$ \\
\hline I & Introversão & 161 & 37,4 \\
\hline N & Intuição & 193 & 44,9 \\
\hline $\mathbf{S}$ & Sensação & $\mathbf{2 3 7}$ & $\mathbf{5 5 , 1}$ \\
\hline F & Sentimento & 75 & 17,4 \\
\hline T & Pensamento & $\mathbf{3 5 5}$ & $\mathbf{8 2 , 6}$ \\
\hline J & Julgamento & $\mathbf{2 9 8}$ & $\mathbf{6 9 , 3}$ \\
\hline P & Percepção & 132 & 30,7 \\
\hline Total de entrevistados* & 430 & \\
\hline
\end{tabular}

* Total de entrevistados com resultado MBTI

Fonte: Dados da pesquisa

Os dados também indicam que há predomínio da preferência $\mathrm{S}$ - sensação $(55,1 \%)$ sobre o $\mathrm{N}$ - intuição $(44,9 \%)$. A diferença entre essas duas letras, entretanto, está mais equilibrada. As pessoas que preferem a sensação são amantes dos prazeres e estão, em geral, contentes. Preferem a arte de viver, no presente, as satisfações de empreendimento e aquisição. Já as pessoas que preferem a intuição são por natureza iniciadores, inventores e promotores e apresentam pouca capacidade de viver a vida e desfrutar o presente.

A maior diferença aconteceu entre as preferências $\mathrm{F}$ - sentimento e o $\mathrm{T}$ - pensamento. Os executivos pesquisados utilizam muito mais a preferência $\mathrm{T}$ - pensamento $(82,6 \%)$ e apenas $17,4 \%$ utilizam a preferência F - sentimento. O percentual mais elevado de executivos que apresentam a preferência $T$ - pensamento não corrobora o que foi discutido no referencial teórico deste artigo sobre os líderes transformacionais. Ou seja, esses líderes empresariais brasileiros apresentam fortes habilidades para atuar, mas valorizam muito mais a racionalidade do que o sentimento. São mais interessadas em coisas do que em relações humanas. Ambiente bastante difícil, portanto, para a atuação da área de recursos humanos no sentido de convencer os pares da importância das pessoas, do capital intelectual, dos talentos, e tantos outros apelos que estão ainda no nível do discurso nas organizações brasileiras.

Há predomínio também da preferência J - julgamento, sobre $\mathrm{P}$ - percepção. Os executivos brasileiros utilizam mais a preferência $J$ - julgamento, 69,3\%, e 30,7\% utilizam a preferência $\mathrm{P}$ - percepção. $\mathrm{Na}$ atitude julgadora, os executivos estão focados em tomar decisões, planejam operações ou organizam atividades. As pessoas que preferem o processo de julgamento parecem ser organizadas, com propósitos e decididas; vivem de acordo com os planos, os padrões e os costumes etêm prazer em ver algo terminado, ficando assim desimpedidas e livres de pensar nisso (Tabela 3). Ou seja, se encontram-se mais divergências, aqui háalguma convergência com a eficiência preconizada pela Teoria Transformacional.

\section{Considerações Finais}

Os dados da pesquisa mostram que os três tipos psicológicos mais presentes entre os grandes executivos brasileiros são: ESTJ (21,6\%), ENTJ (14\%) e ISTJ (13,5\%), totalizando $49,1 \%$.

Esses tipos psicológicos, principalmente o primeiro e o segundo, apresentam como característica principal a facilidade para liderar. Além disso, são determinados e objetivos, ou seja, eficientes como os líderes transformacionais. Apesar de algumas semelhanças entre o que se verifica na teoria sobre os líderes transformacionais e as características encontradas por meio do MBTI, como determinação, eficiência e facilidade para liderar alguns pontos são divergentes.

Segundo a Teoria Transformacional, os líderes consideram-se agentes de mudança e são encontrados principalmente nas organizações que buscam pessoas aptas para conduzir mudanças, mas o tipo psicológico mais encontrado entre os executivos brasileiros (ESTJ) tem como ponto que entra em contradição com este perfil transformacional fato de poderem não enxergar com facilidade a necessidade de mudanças em algumas situações.

Outra divergência é em relação a empatia e a preocupação com os liderados, característica também muito presente entre os líderes transformacionais, mas não tão presente entre os executivos brasileiros. Os nossos executivos, além de poderem ignorar as necessidades alheias (ENTJ) podem ser indelicados e rígidos (ISTJ).

Os três tipos mais encontrados entre os executivos brasileiros de alto escalão têm preferência por caracte- 
rísticas de comportamentos mais objetivos, racionais e planejados. Ou seja, essas características divergem do modelo de liderança idealizado atualmente, modelo que dá atenção aos aspectos relacionados à percepção dos valores e necessidades do outro, do liderado.

$\mathrm{O}$ quadro atual de frequentes mudanças no ambiente de negócios brasileiro, mudanças estas de todo tipo, e cada vez mais presentes, como fusóes e aquisições, produz demandas muito complexas para a liderança empresarial. As características defendidas pela teoria transformacional, que é a mais assumida pela maior parcela da literatura atual sobre liderança, não encontram muito respaldo no contexto brasileiro, marcado pela herança autoritária do legado escravocrata.

No Brasil, portanto, se está mais longe do que perto deste tipo ideal de gestor preconizado pela literatura de matriz norte-americana que fala sobre o líder transformacional. Nas grandes empresas brasileiras, como nossa pesquisa indica, predominam os executivos que aguentam as imensas pressões da cultura de um ambiente de negócios que prioriza a rapidez, a pressa, a superobjetividade para alcançar os resultados esperados, com muita energia e impaciência.

Num ambiente como o brasileiro, é difícil o executivo que quer disputar os altos escalóes das grandes empresas ter uma postura diferente desta. Os executivos precisam, portanto, ser extremamente objetivos para conseguir os ambiciosos resultados deles esperados pelas organizações.

Tudo isso pode explicar, mas não justificar, a dificuldade de nossos executivos enxergarem o outro, o liderado, a falta de nossa capacidade para construir empatia, problemas que se originam de nossa cultura ainda muito autoritária, patriarcal e patrimonialista. Aqui, em nossas empresas, "manda quem pode, obedece quem tem juízo". Mesmo com a deificação da Teoria Transformacional, os valores por ela apregoados não deixam de caminhar no sentido de organizações mais humanizadas, lugares mais adequados para se trabalhar.

\section{REFERÊNCIAS}

ALVESSON, M. Leadership as social integrative action a study of a computer consultancy company. Organizations Studies, Londres. n. 13, p. 185-209, 1992.

AVOLIO, B.; WALDMAN, D.; YAMMARINO, F. Leading in the 1990s: The four I's of transformational leadership. Journal of European Industrial Training. UK, v. 25, n. 4, p. 9-16, 1991.

BASS, B. Leadership and performance beyond expectations. New York: Free Press, 1985.

BASS, B. M.; AVOLIO, B. J.The implications of transactional and transformational leadership for individual, team and organizational development.

Research in Organizational Change and

Development, Greenwich, v. 4, p. 231-272, 1990.

BASS, B. M.; AVOLIO, B. J.Transformational leadership and organizational culture. Public Administration Quarterly, Greenwich, v. 17, n. 1, p. 112-121, 1994.

BASS, B. M.; AVOLIO, B. J. Shatter the Glass Ceiling: Women May Make Better Managers. Human Resource Management, New York, v. 33, n. 4; p. 549- 561, 1994.

BASS, B. M.; AVOLIO, B. J. Transformational leadership and organizational culture. International Journal of Public Administration, New York, v. 17, n. 3,4; p. 541-555, 1995.

BERGAMINI, C. W. Liderança administração do sentido. São Paulo: Atlas, 1994.

BLAKE, R.; MOUTON, J. S. O grid gerencial. 3. ed. São Paulo: Pioneira, 1978.

BOWDITCH, J. L.; BUONO, A. F. Elementos do comportamento organizacional. São Paulo: Pioneira Thomson, 2002.

BURNS, J. M. Leadership. New York: Harper \& Row Publishers, 1978.

FIEDLER, F. E. Liderança e administração eficaz. São Paulo: Pioneira: Editora da Universidade de São Paulo, 1981. 
HERSEY, P.; BLANCHARD K. A Mudança organizacional através da liderança eficaz. São Paulo: Multimedia Tecnologia Educacional, 1980.

HIRSH, S. K.; KUMMEROW, J. M. Introdução aos tipos psicológicos nas organizações. Palo Alto, Califórnia: CCP - Consulting Psychologists Press, Inc., 1995.

HOLLANDER, E. P. Leadership dynamics: a practical guide to effective relationships. New York: Free Press, 1978.

KIPNIS, D. Interacion between members of bombers crews as a determinant of sociometric choice. Journal of Human Relations. Ohio, n. 10, p. 26-70, 1957.

KIRKBRIDE. P. Developing transformational leaders: the full range leadership model in action. Journal Industrial and Commercial Training, UK, v. 38, n. 1, p. 2332,2006 .

LEAVITT, H. Some effects of certain communication patterns on group performance. Journal of Abnormal and Social Psychology, n. 46, p. 38-50, 1951.

MATTAR, F. N. Pesquisa de marketing: metodologia, planejamento. 5. ed. São Paulo: Atlas, 1999.

MONTANA, J. P.; CHARNOV, H. B. Administração.

São Paulo: Saraiva, 1998.

MYERS, I. B. Gifts Differing. Palo Alto, Califórnia: CCP - Consulting Psychologists Press, Inc., 1980.

MYERS, I. B.; MCCAULLEY, M. H. Manual: a guide to the development and use of the Myers-Briggs Type Indicator. Palo Alto, Califórnia: CCP - Consulting Psychologists Press, Inc., 1985.

\section{MYERS, I. B. Introdução à teoria dos tipos}

psicológicos: um guia para entender os resultados do Myers-Briggs Type Indicator. Palo Alto, Califórnia: CCP Consulting Psychologists Press, Inc., 1995.

MYERS, I. B.; MYERS, P. B. Ser humano é ser diferente: valorizando as pessoas por seus dons especiais. São Paulo: Editora Gente, 1997.

NORTHOUSE, P. G. Leadership: theory and practice. Londres: Sage Publications, 2001.

\section{ROBBINS, S. P. Comportamento organizacional.}

Tradução técnica: Reynaldo Marcondes. 9. ed. São Paulo: Prentice Hall, 2002.

ROBBINS, S. P. Administração. São Paulo. Saraiva, 2000.

ROSENER, J. B. America's competitive secret: women managers. Oxford University Press, New York, NY, 1995.

SADLER, P. Leadership and organizational learning. In: DIEKERS, Meinolf et al. Handbook of organizational learning and knowledge. Oxford: Oxford University Press, p. 415-427, 2003.

SCHEIN, E. Organizational culture and leadership. San Francisco: Jossey-Bass, 1985.

SIMS, H. P.; Lorenzi, P. The new leadership paradigm. Newbury Park: Sage, 1992.

STOGDILL, R. M. Personal Factors Associated with Leadership: A survey of literature. Journal of Psychology, 25, p. 35-71, 1948.

STONER, J. A.; Freeman, R. E. Administração. Rio de Janeiro: LTC, 1999.

TANURE, B; CARVALHO NETO, A; ANDRADE, J. Executivos: sucesso e (in)felicidade. Rio de Janeiro: Elsevier, 2007.

TICHY, N.; DEVANNA, M. The transformational leader. New York: John Wiley, 1986.

YULK, G.; Wall, S.; LEPSINGER, R. Preliminary report on validation of the management practices survey. In: CLARK, K. E.; CLARK, M. B. Measures of leadership. New Jersey: Leadership Library of America, 1990.

YULK, G.; FLEET, D.Theory and research on leadership in organizations. In: DUNNETTE, M. et al. Handbook of industrial and organization psychology. 2. ed. Palo Alto, Califórnia: Consulting Psychologists press, p. 147197, 1994. 